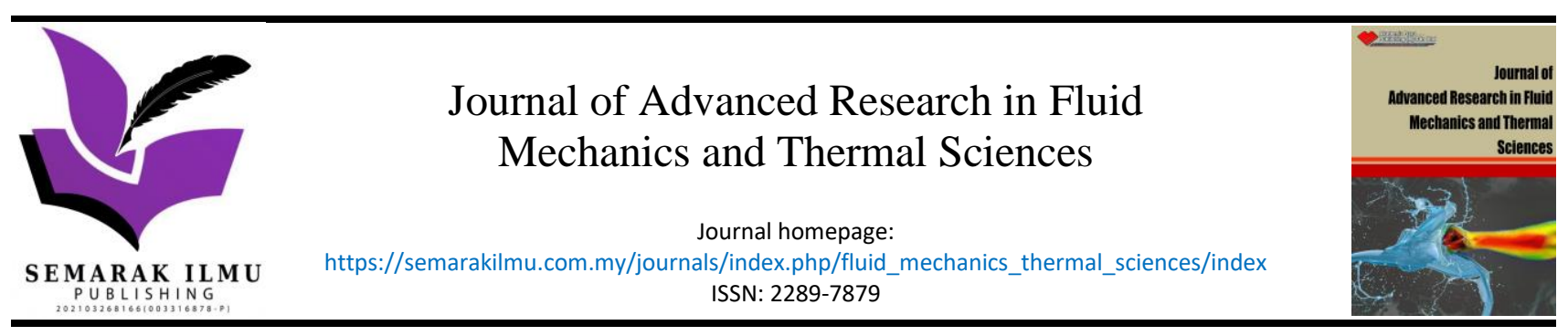

\title{
Carbon Emission Reduction Strategies Through Cleaner Production at Coconut Milk Processing Plant
}

\author{
Mohamed Hafiz Md Isa ${ }^{1,}{ }^{*}$, Mohamad Fahim Ikhwan Najamuddin ${ }^{1}$ \\ Faculty of Mechanical Engineering, Universiti Teknikal Malaysia Melaka (UTeM), Hang Tuah Jaya, 76100, Durian Tunggal, Melaka
}

\section{ARTICLE INFO}

\section{Article history:}

Received 27 July 2021

Received in revised form 25 October 2021

Accepted 10 November 2021

Available online 17 December 2021

Keywords:

Cleaner production; green industry; statistical analysis

\section{ABSTRACT}

The manufacturing industry is one of the most influential sectors contributing to greenhouse gas emissions. As the manufacturing industry strives to achieve its profit goal, most of them face various circumstances to control the rising carbon emissions from the energy, raw material consumption, and waste generations due to production activities. Therefore, it is difficult to quantify the amount of carbon emission reduction if the adjustment is not established according to the manufacturing output. This research concentrates on evaluating energy consumption and waste generation using a statistical approach by a coconut milk processing plant. This research aims to estimate the reduction of greenhouse gas emissions, mainly carbon dioxide $\left(\mathrm{CO}_{2}\right)$. The baseline models of energy consumptions and waste generations were constructed using single and multiple linear regression methods. Besides, it investigates the performance of ultimate models of electrical consumption, water consumption, fuel consumption, solid waste generation, and wastewater generations using statistical analysis that involves coefficient of correlation, coefficient of determination, analysis of variance (ANOVA), etc. It indicates that with the implementation of the cleaner production (CP) strategy, the plant had reduced 10,474.94 tons of $\mathrm{CO}_{2}$ and 2,579.67 tons of $\mathrm{CO}_{2}$ in 2018 and 2019, respectively. This study is an aid to the management and engineers of the industry to investigate their accomplishment in reducing environmental impacts caused by production activities from any implementation made such as CP and green industry practices.

\section{Introduction}

Naturally, a natural process called photosynthesis generates carbon dioxide $\left(\mathrm{CO}_{2}\right)$ by combining oxygen and other organic substances. On the other hand, human activities such as land-use changes, industrial processes, fossil fuel combustion, and biomass burning led to $\mathrm{CO}_{2}$ emissions. Likewise, the atmospheric concentration of $\mathrm{CO}_{2}$ emission has risen tremendously over the years due to rigorous human activities [1]. Nowadays, the statistical rise of global warming and anthropogenic climate change is primarily due to production activities. Most manufacturing industries have been directly involved in the increased concentrations of atmospheric $\mathrm{CO}_{2}$ emission. Besides, $\mathrm{CO}_{2}$ emission, known as a greenhouse gas, is considered a harmful gas due to rising sea levels and global warming. Annual

\footnotetext{
* Corresponding author.

E-mail address: mohamedhafiz@utem.edu.my
}

https://doi.org/10.37934/arfmts.90.1.146153 
environmental research reported the active melting occurrence of global ice sheets and glaciers, consequently causing a high-water volume to the oceans.

Technically, a by-product of chemical reactions is commonly generated in most manufacturing production processes. Therefore, numerous industrial processes emit a significant amount of $\mathrm{CO}_{2}$ into the atmosphere. A study in 2011 reported that industrial revolutions have instigated $4 \%$ of human $\mathrm{CO}_{2}$ emissions and produced 1.7 billion tons of $\mathrm{CO}_{2}$ gas emission [2]. Among the main activities contributing to $\mathrm{CO}_{2}$ emission is fossil fuel burning, which converts the energy in mechanical and chemical processes into electricity and transportation [3-5]. Hence, the quest to reduce $\mathrm{CO}_{2}$ emission is paramount to diminish global warming and climate change without adversely affecting industrial production, economy, and net worth.

This study focuses on measuring and verifying $\mathrm{CO}_{2}$ emission reduction from implementing the cleaner production (CP) strategy using a statistical approach. CP is an integrated preventative environmental strategy applied to the manufacturing processes and activities through conserving the energy and raw material, reducing the toxicity of emission, removing toxic material, and minimizing wastes at the source of generation [6]. Since most of the $\mathrm{CO}_{2}$ emissions generated in the manufacturing industry are contributed by energy consumption and waste generations, this research will focus on studying energy, waste, and CP option evaluation to reduce the emission of $\mathrm{CO}_{2}$ [7-10].

$\mathrm{CP}$ is a practical approach focused on preventive strategies to minimize the environmental impact of the manufacturing sectors. In identifying CP options, a methodology is developed based on reducing carbon emission sources from manufacturing processes and activities [11]. Five entities are involved in production processes and activities: consumption of electricity (EEC), fuel consumption (FC), and water consumption (WC), and generation of solid waste (SWG), and wastewater generation (WWG) that generates $\mathrm{CO}_{2}$ emission [12]. These dependent variables are influenced by independent variables such as production output, working hours, and other variables $[13,14]$. Furthermore, there is a need to investigate the influence of these independent variables to estimate the reduction of the carbon emission from the implementation of CP. Therefore, statistical analysis using the single and multiple linear regression techniques were used to evaluate these variables. A similar approach was used to assess the independent and dependent variables impact of the $\mathrm{CO}_{2}$ emission from the refining the petroleum product using collected data from 1980 to 2010 [15].

\section{Methodology}

In achieving the objectives, a referable methodology framework (Figure 1) was constructed based on a comprehensive observation. A thorough literature review was performed to determine possible associated problems by reviewing journals, articles, and books. Subsequently, data collection through either desktop and detailed onsite audit was performed based on verified procedures and techniques to obtain a good and precise result. The collected and recorded data undergo data evaluation and mathematical analysis using statistical software. This software generates a linear regression model. Next, the relationship between the independent and dependent variables was made using statistical analysis by evaluating the correlation, $r$, goodness of fit, $R^{2}$, adjusted $R^{2}$, and $P$-value [14].

This research also performed the time-dependent analysis by comparing the manufacturing plant energy and raw material conserved, waste generation, and annual $\mathrm{CO}_{2}$ emission in three years. As a result, any changes in $\mathrm{CO}_{2}$ emission reduction, energy conservation, and raw material and waste generations were compared for further improvements. 


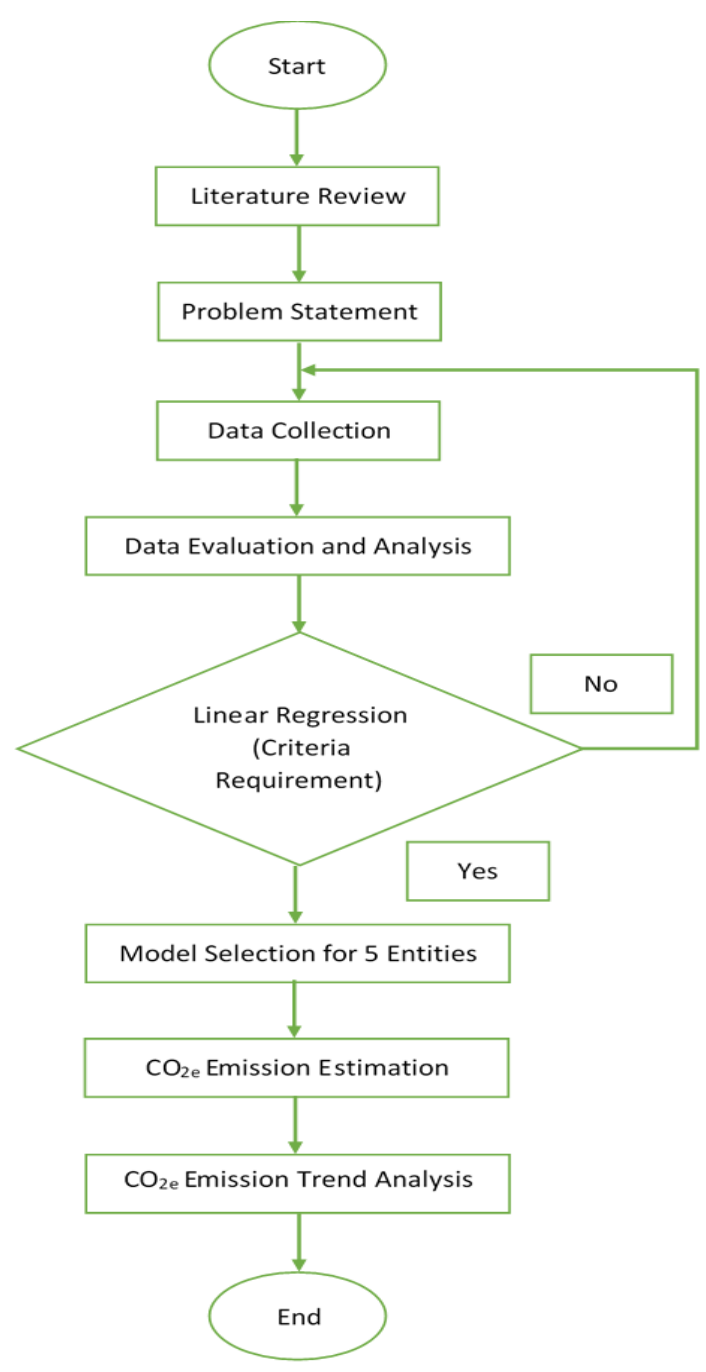

Fig. 1. Research methodology

Statistical Package for Social Science (SPSS) software was used to determine the statistical relationship between the independent and dependent variables from the single and multiple linear regression analysis. Five dependent variables were involved, i.e., electricity consumption, fuel consumption, water consumption, wastewater generation, and solid waste generation. In comparison, three independent variables produced three types of products: the Coconut Cream Powder (CCP), Low-Fat Desiccated Coconut (LFDC), and Testa/Brown Skin (TBS).

The results of the SPSS software involved the value of standard error, $t$-stat, $p$-value, coefficient, $\mathrm{F}$ value, and others. The results were evaluated to select the best model to predict $\mathrm{CO}_{2}$ emission reduction. The model is validated by comparing the simulated values with the observed value obtained from a detailed onsite audit [16]. The model represents the relationship between the predictable dependent variables $(\mathrm{Y})$ and a set of independent variables $(\mathrm{X})$. The multiple linear regression model is

$Y=b_{0}+b_{1} X_{1}+b_{2} X_{2}+\ldots+b_{k} X_{k}$

where

$\mathrm{Y}=$ dependent variable

$b_{1}=$ first independent variable regression coefficient

$b_{2}=$ second independent variable regression coefficient 
$X_{1}=$ first independent variable

$\mathrm{X}_{2}=$ second independent variable

After selecting the best model, the $\mathrm{CO}_{2}$ emission was calculated by multiplying the dependent variables with the emission factor. Table 1 indicates the emission factors used in this research.

Table 1

\begin{tabular}{ll}
$\mathrm{CO}_{2}$ emission factor [12] \\
\hline Entity & Emission Factor \\
\hline Water Consumption & $0.800 \mathrm{~kg} \mathrm{CO}_{2} / \mathrm{m}^{3}$ \\
Electricity Consumption & $0.694 \mathrm{~kg} \mathrm{CO}_{2} / \mathrm{kWh}$ \\
Fuel Consumption & $2.7 \mathrm{~kg} \mathrm{CO}_{2} \mathrm{~kg}$ solid fuel \\
Wastewater Generation & $1.000 \mathrm{~kg} \mathrm{CO}_{2} / \mathrm{kg} \mathrm{COD} \mathrm{removed}$ \\
Solid Waste Generation & $3.700 \mathrm{~kg} \mathrm{CO}_{2} / \mathrm{kg}$ solid waste \\
\hline
\end{tabular}

\section{Results and Discussion}

This section will discuss the findings of this project. First, in 2017, this project conducted the green industry audit to collect the baseline data, which was used to compare the $\mathrm{CO}_{2}$ emission reduction in 2018 and 2019. Then, recorded data were used to identify the $\mathrm{CO}_{2}$ emission model equation based on thorough observation and measurement. The best model selected for this research is highly essential to calculate $\mathrm{CO}_{2}$ emissions precisely for the industry to reduce the industry's time, cost, and commitments. Three regressors are identified in this research, and seven total possible statistical models are identified for each entity, and a formula calculates this assumption, $2^{\mathrm{k}}-1$, where $\mathrm{k}=3$. The possible statistical models in this research are shown in the Table 2 below.

Table 2

Possible regression equation based on three regressors

\begin{tabular}{lll}
\hline Model & Regressor & General equation of the regression \\
\hline 1 & CCP & $y=\beta_{0}+\beta_{1} C C P$ \\
2 & LFDC & $y=\beta_{0}+\beta_{1}$ LFDC \\
3 & TBS & $y=\beta_{0}+\beta_{1}$ TBS \\
4 & CCP, LFDC & $y=\beta_{0}+\beta_{1} C C P+\beta_{2} L F D C$ \\
5 & CCP, TBS & $y=\beta_{0}+\beta_{1} C C P+\beta_{2}$ TBS \\
6 & LFDC, TBS & $y=\beta_{0}+\beta_{1}$ LFDC $+\beta_{2}$ TBS \\
7 & CCP, LFDC, TBS & $y=\beta_{0}+\beta_{1} C C P+\beta_{2} L F D C+\beta_{3}$ TBS \\
\hline$*$ CCP: Coconut Cream Powder, LFDC: Low Fat Desiccated Coconut, TBS: Testa/Brown Skin
\end{tabular}

The best regression model will be selected based on the criteria and requirements, referring to the Table 3 below.

Table 3

Criteria references to select the best statistical model

\begin{tabular}{ll}
\hline Statistical Analysis & Best Criteria \\
\hline Pearson correlation, $r$ & The higher is better \\
Determination of coefficient, $\mathrm{R}^{2}$ & The higher is better \\
VIF & $<10$ \\
Tolerance & $>0.1$ \\
F-test & P-value $<0.05$ \\
\hline
\end{tabular}


Next, Table 4 indicates the example of statistical analysis on the impact of independent variables on fuel consumption.

\section{Table 4}

Example of the result from the statistical analysis

\begin{tabular}{|c|c|c|c|c|c|c|c|c|}
\hline $\begin{array}{l}\text { Dependent } \\
\text { Variables }\end{array}$ & Regressor & $r$ & $\mathrm{R}^{2}$ & $\begin{array}{l}\text { Adj } \\
R^{2}\end{array}$ & $\begin{array}{l}\mathrm{P}- \\
\text { value }\end{array}$ & $\begin{array}{l}\text { Tol > } \\
0.1\end{array}$ & $\begin{array}{l}\text { VIF }< \\
10\end{array}$ & Regression Equation \\
\hline Fuel & $\mathrm{CCP}$ & 0.818 & 0.670 & 0.637 & 0.001 & 1.000 & 1.000 & $y=758319.620+4.332 C C P$ \\
\hline \multirow[t]{12}{*}{ Consumption } & LFDC & 0.671 & 0.450 & 0.395 & 0.017 & 1.000 & 1.000 & $y=1158429.661+9.395$ LFDC \\
\hline & TBS & 0.518 & 0.268 & 0.195 & 0.085 & 1.000 & 1.000 & $y=1594805.309+20.441 T B S$ \\
\hline & CCP, LFDC & 0.820 & 0.673 & 0.600 & 0.007 & 0.391 & 2.557 & $y=739764.646+3.992 C C P+$ \\
\hline & & & & & & 0.391 & 2.557 & 1.153LFDC \\
\hline & $\mathrm{CCP}, \mathrm{TBS}$ & 0.853 & 0.728 & 0.667 & 0.003 & 0.872 & 1.147 & $y=585155.374+3.844 C C P+$ \\
\hline & & & & & & 0.872 & 1.147 & 10.183TBS \\
\hline & LFDC, TBS & 0.678 & 0.459 & 0.339 & 0.063 & 0.558 & 1.791 & $y=1130174.452+8.200$ LFDC \\
\hline & & & & & & 0.558 & 1.791 & $+5.072 \mathrm{TBS}$ \\
\hline & CCP, LFDC, & 0.865 & 0.748 & 0.654 & 0.009 & 0.345 & 2.902 & $y=563373.446+4.847 C C P-$ \\
\hline & TBS & & & & & & & 4.267LFDC + 15.502TBS \\
\hline & & & & & & 0.221 & 4.533 & \\
\hline & & & & & & 0.492 & 2.033 & \\
\hline
\end{tabular}

According to Table 4, from a single regression section, it can be concluded that the variation of fuel consumption (FC) is explained by Testa Brown Skin (TBS) by $26.8 \%$. By going through the equation list, the response variable's interpretation is explained better by more than one independent variable. For example, $66.7 \%$ variation of fuel consumption is explained by CCP and TBS. Besides, two equations are significant, based on the $P$-value. $R^{2}$ and adjusted $R^{2}$ of these models are 0.670 and 0.667 , respectively. However, compared to the single variable model, the multiple variables model holds the highest $R, 0.853$, indicating a strong positive correlation between variables. Therefore, the highest adjusted $R^{2}$ is considered, and the best statistical model is $y=585155.374+3.844 C C P+$ 10.183TBS. Likewise, no multicollinearity is detected since tolerance and VIF value are within the rule. Table 5 indicates the selected statistical equation model for all the dependent variables.

\section{Table 5}

Selected statistical equation model for dependent variables

\begin{tabular}{ll}
\hline Dependent Variables & Regressor \\
\hline Electricity Consumption & $\mathrm{y}_{1}=207160.942+0.106 C C P-1.068 T B S$ \\
Fuel Consumption & $\mathrm{y}_{2}=585155.374+3.844 C C P+10.183 T B S$ \\
Water Consumption & $\mathrm{y}_{3}=6869.807+0.004 C C P$ \\
Solid Waste Generation & $\mathrm{y}_{4}=42426.620-0.208 C C P+0.655 \mathrm{LFDC}+1.447 \mathrm{TBS}$ \\
Wastewater Generation & $\mathrm{y}_{5}=4808.865+0.003 \mathrm{CCP}$ \\
\hline
\end{tabular}

The evaluation process on the statistical model is done accordingly, with significant products per kilogram yield from industry activities that influence the various values of the five entities known to contribute to $\mathrm{CO}_{2}$ emission in the coconut milk processing industry. This screening process mathematically provides a better estimation of the $\mathrm{CO}_{2}$ emission by the industry in a particular month. In this study, the best models are selected from each entity involving EEC, FC, WC, SWG, and WWG by the screening process discussed earlier and prescribed as a baseline model constructed by the sample data collected in 2017. Hence, each of them is used to predict $\mathrm{CO}_{2}$ emission by the coconut milk processing industry monthly, supported by a formula developed by the Intergovernmental Panel on Climate Change (IPCC). 
The model validation involves comparing the model results with empirical evidence collected during the detailed audit. In this case, the amount of $\mathrm{CO}_{2}$ emission simulated from these models is $6,963.64$ tonnes of $\mathrm{CO}_{2}$ emission, while the amount of $\mathrm{CO}_{2}$ emission calculated from the onsite observed data is $6,997.16$ tonnes of $\mathrm{CO}_{2}$ emission. The differences between these values are $4.23 \%$.

\section{$3.1 \mathrm{CO}_{2}$ Emission Reduction in 2018}

Figure 2 shows the differences between the adjusted baseline $\mathrm{CO}_{2}$ emission and actual $\mathrm{CO}_{2}$ emission in 2018.

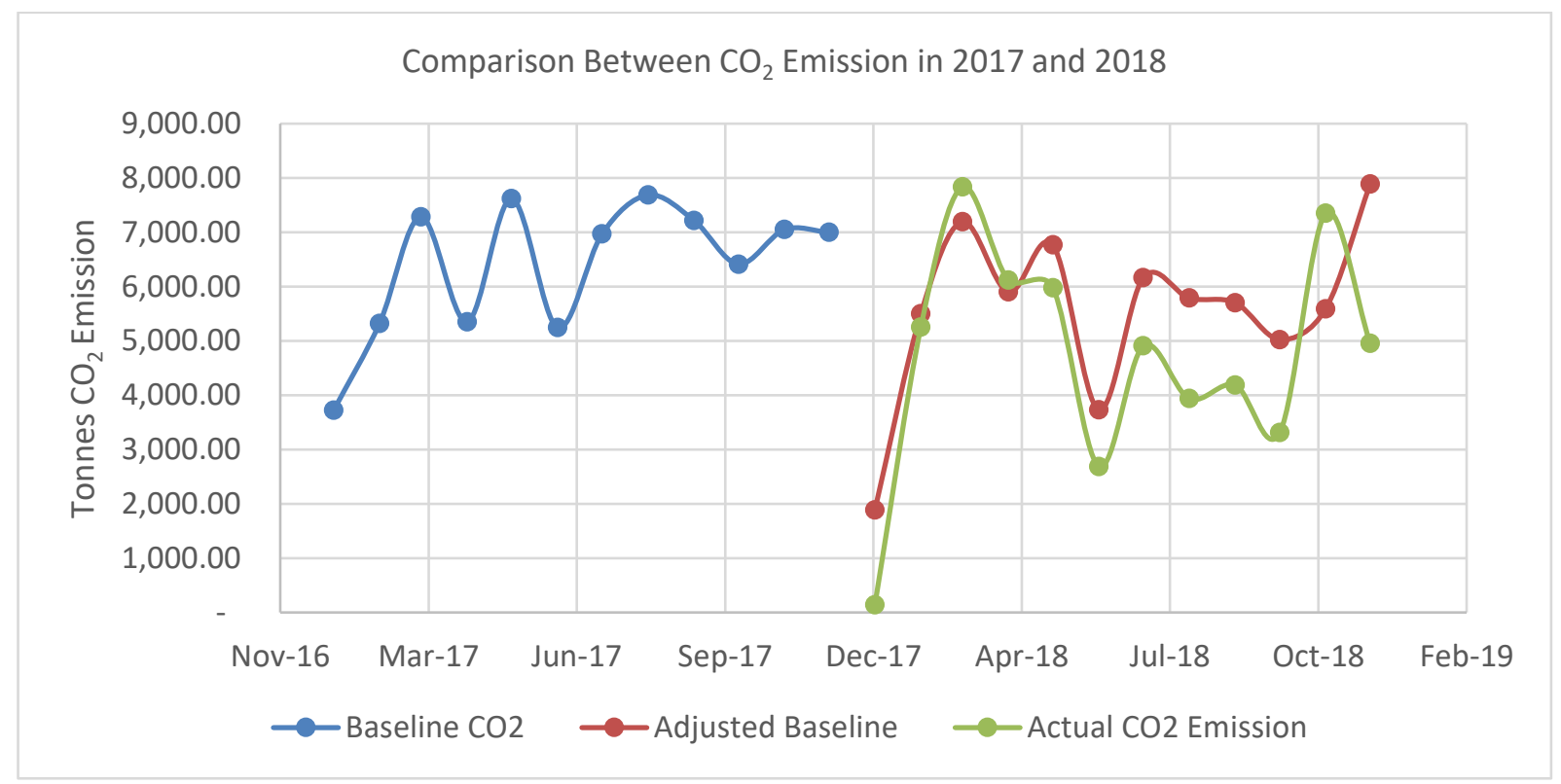

Fig. 2. Theoretical (adjusted baseline) $\mathrm{CO}_{2}$ emission and actual $\mathrm{CO}_{2}$ emission in 2018

As portrayed in the figure above, the $\mathrm{CO}_{2}$ emission initially rises drastically from January to March for the actual and theoretical values. Similarly, no reduction in $\mathrm{CO}_{2}$ emission is seen in March and April. However, the emission started to reduce starting May until October, comprising six consecutive months of good performance. At the end of the year, the emission started rising in November. A rapid emission increment is detected, i.e., 1,755.90 tonnes of $\mathrm{CO}_{2}$ emissions upon calculation of differences between theoretical and actual value in November. The carbon emission is high. Technically, excessive $\mathrm{CO}_{2}$ emission is affected by the increase in production activities.

Consequently, electricity consumption, fuel, water, and waste generation increase and boost $\mathrm{CO}_{2}$ emissions. Nevertheless, the reduction of $\mathrm{CO}_{2}$ emission continues in December, where 2,934.82 tonnes of $\mathrm{CO}_{2}$ emission are successfully reduced. This scenario might be influenced by good green practices implemented by the industry, such as housekeeping practices, practicing reduce, reuse, and recycle (3R), and operation modification, which is commonly done by combining two or more processes to eliminate unnecessary procedures. In total, the plant had had successfully reduced $\mathrm{CO}_{2}$ emissions by $10,474.94$ tonnes $\mathrm{CO}_{2}$ or $15.6 \%$ in 2018 . 


\section{$3.2 \mathrm{CO}_{2}$ Emission Reduction in 2019}

Figure 3 shows the differences between the adjusted baseline $\mathrm{CO}_{2}$ emission and actual $\mathrm{CO}_{2}$ emission in 2019.

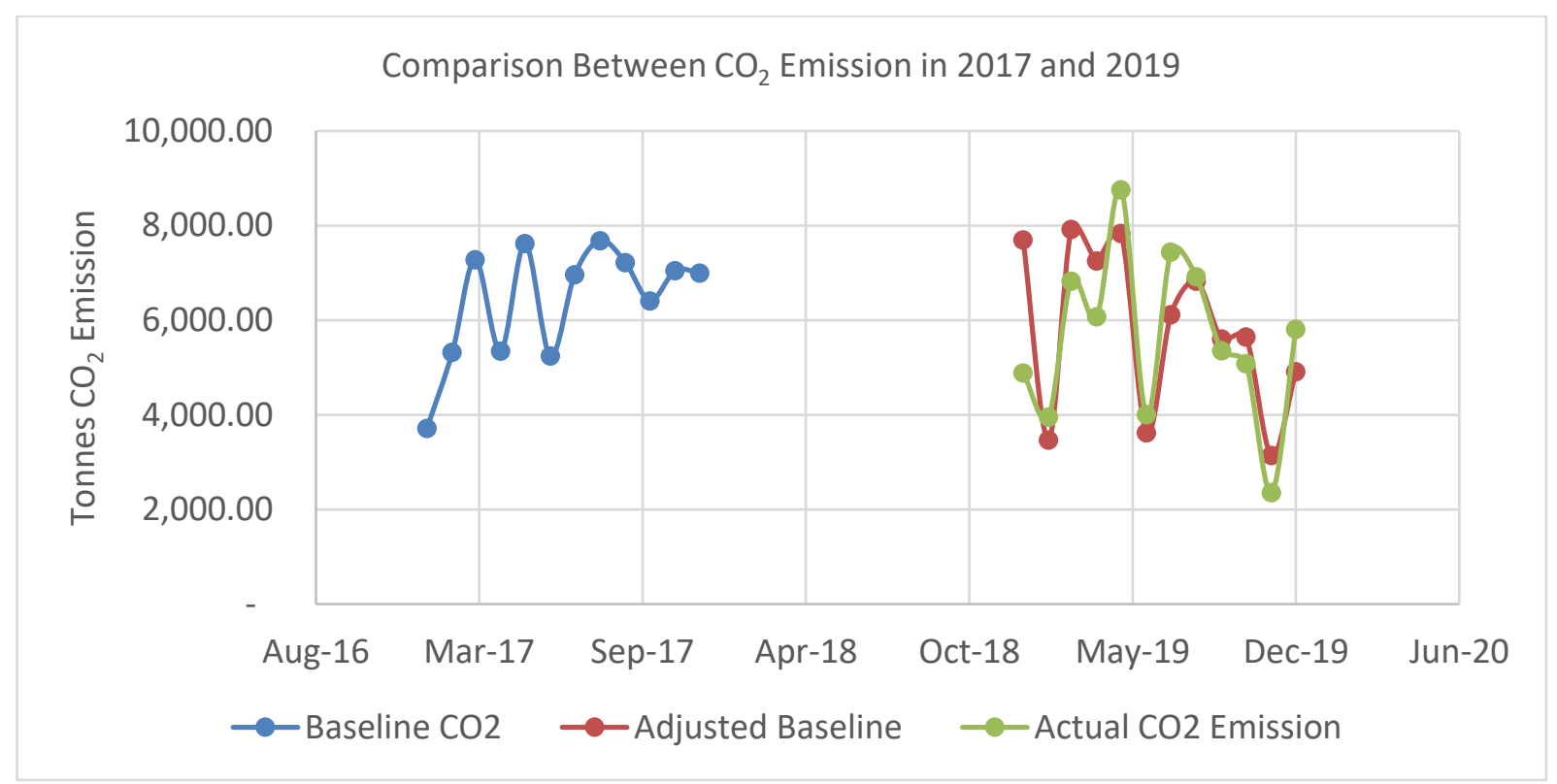

Fig. 3 Theoretical (adjusted baseline) $\mathrm{CO}_{2}$ emission and actual $\mathrm{CO}_{2}$ emission in 2019

A considerable gap between the theoretical and actual value was spotted in the first month, indicating that a large amount of $\mathrm{CO}_{2}$ emission reduction had been achieved. However, between May and July, a continuous increment of the industry's emissions is observed towards the middle of the year. However, in June, both actual and theoretical $\mathrm{CO}_{2}$ values fall drastically to 4,005.54 and 3,619.31 tonnes $\mathrm{CO}_{2}$, respectively. The low $\mathrm{CO}_{2}$ emission is affected by decreasing production activities. Likewise, the $\mathrm{CO}_{2}$ emission reduction continues towards the end of the year (September, October, and November). Finally, by analyzing the trend comprehensively, the coconut milk processing industry had successfully controlled the emissions of $\mathrm{CO}_{2}$, with a total of 2,579.67 tonnes of $\mathrm{CO}_{2}$, or a $3.68 \%$ reduction in 2019 .

\section{Conclusions}

In summary, a statistical study for estimating $\mathrm{CO}_{2}$ emission concerning related entities such as electrical and fuel consumption, solid waste, and wastewater generation using a simple and multiple linear statistical regression model was developed to deal with uncontrolled $\mathrm{CO}_{2}$ energy losses due to production activities in the industry. Furthermore, baseline $\mathrm{CO}_{2}$ entity models were developed using single and multiple regression to predict $\mathrm{CO}_{2}$ emission in the studied years.

Three years of data sets have been measured and analyzed in this research to achieve the stated objectives. The first data sets represented by the 2017 data were used for modeling purposes to obtain baseline models as the initial prediction step. Meanwhile, the second and third data sets were represented by the 2018 and 2019 data for estimation purposes. As a result, based on the reasonable prediction of $\mathrm{CO}_{2}$ emissions in the coconut milk processing industry in 2018, 10,474.94 tonnes of $\mathrm{CO}_{2}$ had been successfully reduced, while a reduction of 2,579.67 tonnes $\mathrm{CO}_{2}$ was achieved in 2019 . Therefore, a comprehensive cleaner production (CP) implementation is highly recommended to meet sustainable development goals, especially in the manufacturing industry. Consequently, energy, 
water, and raw material consumption can be lessened while enhancing the industry's quality, productivity, and environmental health.

The limitation of this paper is that the estimation of $\mathrm{CO}_{2}$ emission is based on the data obtained from the detailed onsite audit and a single case study. Therefore, this paper proposes to improve the model by examining the model at another plant in the same industry as future work. Besides, this paper also proposes developing a model for forecasting the $\mathrm{CO} 2$ emission as this would benefit the industry to plan their production to reduce their $\mathrm{CO}_{2}$ emission.

\section{References}

[1] United Nations Department of Public Information. "Sustainable Development Goals." 2020.

[2] Le Quéré, Corinne, Robert J. Andres, T. Boden, Thomas Conway, Richard A. Houghton, Joanna I. House, Gregg Marland et al. "The global carbon budget 1959-2011." Earth System Science Data Discussions 5, no. 2 (2012): 11071157. https://doi.org/10.5194/essd-5-165-2013

[3] Department of Environment. "Cleaner Production (CP) Training Programme for Small and Medium Enterprise (SME)." 2020.

[4] Ee, Jonathan Yong Chung, Jin Yuan Chan, and Gan Lik Kang. "Carbon reduction analysis of Malaysian green port operation." Progress in Energy and Environment 15 (2021): 1-7.

[5] Hashim, Fazlini, Aida Mauziah Benjamin, and Syariza Abdul-Rahman. "Estimation of Carbon Dioxide Emissions in a Waste Collection Vehicle Routing Problem." Journal of Advanced Research in Fluid Mechanics and Thermal Sciences 53, no. 2 (2019): 204-212.

[6] United Nation Environment Programme. "International Declaration on Cleaner Production: Implementation Guidelines for Facilitating Organizations." United Nations Publication, Paris, 2001.

[7] Department of Environment. "Department of Environment: Success Story of Cleaner Production Implementation in Malaysia." 2020.

[8] Hafiza, M. I. M., Z. M. Zulfattahb, N. A. Munajatc, A. B. F. Sakinahc, and H. M. Asyrafc. "Cleaner Production Implementation at Chicken Slaughtering Plant." International Journal of Applied Environmental Sciences 11, no. 2 (2016): 515-523.

[9] Rahim, Razuana, and Abdul Aziz Abdul Raman. "Cleaner production implementation in a fruit juice production plant." Journal of Cleaner Production 101 (2015): 215-221. https://doi.org/10.1016/j.jclepro.2015.03.065

[10] Rahim, Razuana, and Abdul Aziz Abdul Raman. "Carbon dioxide emission reduction through cleaner production strategies in a recycled plastic resins producing plant." Journal of cleaner production 141 (2017): 1067-1073. https://doi.org/10.1016/i.jclepro.2016.09.023

[11] Rahim, Razuana, Abdul Aziz Abdul Raman, Raja Shazrin Shah Raja Ehsan Shah, and Kai Shing Chiong. "A methodology for identifying cleaner production options to reduce carbon emission in the manufacturing industry." Research Communication in Engineering Science \& Technology $4 \quad$ (2020): 24-37. https://doi.org/10.22597/rcest.v4.81

[12] Jabatan Alam Sekitar Malaysia. "Guidelines for green industry auditor." 2014.

[13] Isa, Mohamed Hafiz Md, Mohamad Fani Sulaima, Norhidayah Mohamad, Fakulti Kejuruteraan Elektrik, and Fakulti Pengurusan Teknologi Dan Teknousahawanan. "The impact of independent variables on energy saving measures implementation: A case study in healthcare services." Proceedings of Mechanical Engineering Research Day 2020 (2020): 216-217.

[14] Efficiency Valuation Organization. "International Performance Measurement and Verification Protocol, Efficiency Valuation Organization." 2012.

[15] Keat, Sim Chong, Beh Boon Chun, Lim Hwee San, and Mohd Zubir Mat Jafri. "Multiple regression analysis in modelling of carbon dioxide emissions by energy consumption use in Malaysia." In AIP Conference Proceedings, vol. 1657, no. 1, p. 050005. AIP Publishing LLC, 2015. https://doi.org/10.1063/1.4915185

[16] Dijkstra, Paul, Sanderine Nonhebel, Cees Grashoff, Jan Goudriaan, and Siebe C. van de Geijn. "Response of growth and $\mathrm{CO} 2$ uptake of spring wheat and faba bean to $\mathrm{CO}_{2}$ concentration under semifield conditions: comparing results of field experiments and simulations." In Carbon dioxide and terrestrial ecosystems, pp. 251-264. Academic Press, 1996. https://doi.org/10.1016/B978-012505295-5/50015-X 